\title{
La historia es una
}

\section{María de los Ángeles Romero Frizzi}

$\mathrm{E}$ STE NÚMERO de Desacatos está dedicado a la reflexión sobre la etnohistoria. Una vez más la antigua pregunta vuelve a preocuparnos: ¿Qué es etnohistoria? ¿ ¿Es una especialidad de la historia o es una disciplina independiente? ¿Por qué volvemos con la misma inquietud? ¿Vale la pena la insistencia? Pareciera como si la larga trayectoria de esta disciplina, más los centenares de artículos, capítulos y libros que han sido escritos por la pluma de los etnohistoriadores, no fueran suficientes para probar que es un campo fértil y fructífero.

Dado que los etnohistoriadores padecemos esta angustia existencial, me parece interesante saber si a los historiadores les ha ocurrido lo mismo. Permítanme, de momento, iniciar esta reflexión manteniendo una diferencia entre historia y etnohistoria, como si ambas

MARÍA DE LOS ÁNGELES ROMERO FRIZZI: Investigadora del INAHOaxaca.

${ }^{1}$ La palabra etnohistoria se utilizaba en forma esporádica desde principios del siglo XX, pero en forma más sistemática fue empleada en la década de 1940 por arqueólogos, historiadores y antropólogos norteamericanos para describir sus estudios sobre la historia de los pueblos nativos del Nuevo Mundo (Cohn, 1971). Existen numerosos escritos que en distintos momentos han reflexionado sobre las características del quehacer del etnohistoriador. El escrito de Bernard Cohn (1971) contiene un buen resumen del método etnohistórico; también pueden verse los trabajos Vansina (1961, 1962), Spores (1973), Spalding (1974), Martínez Marín (1976), Axtell (1979), Rojas (1982), Trigger (1982), LeGoff (1983), Harvey y Prem (1983), Romero Frizzi (1994), De Rojas (1989), entre otros muchos.

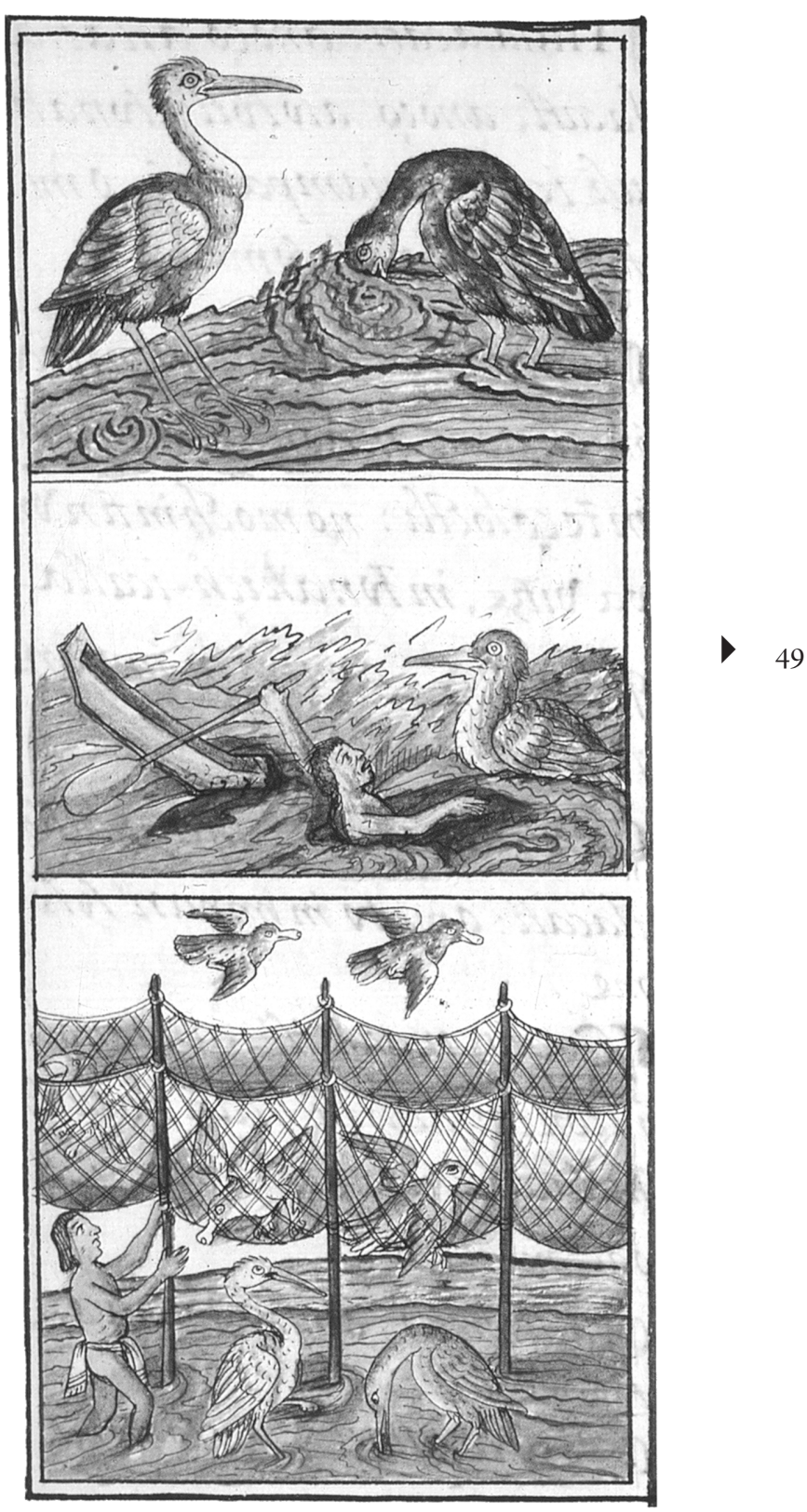

Cazando pájaros en el lago; Códice Florentino 
disciplinas fueran claramente distintas. Pensemos en la historia como la ciencia del pasado, aquella que construye su conocimiento a partir del análisis de las llamadas fuentes históricas situándolas en el contexto en que fueron producidas. Digamos que la etnohistoria es el estudio que combina las herramientas de la historia y la antropología para conocer el pasado de los pueblos de tradición diferente a la occidental. Esta división es momentánea, al final de este trabajo volveré sobre ella.

En efecto, también los historiadores se han preocupado por meditar sobre su materia de estudio y muchas veces se han cuestionado: ¿Por qué es relevante la historia? ¿Para qué mirar al pasado? ¿Cuál es la relación entre la historia y las otras ciencias sociales? Es más, unos de los más prominentes historiadores, aquellos que han dejado una huella profunda en los anales de su disciplina, han respondido a estas inquietudes con obras maestras. Quizás mis favoritos sigan siendo, a pesar de los años, Marc Bloch $^{2}$ y Lucien Febvre, ${ }^{3}$ en especial el primero con su libro publicado después de su muerte, Apologie pour l'Histoire ou Métier d'Historien [Apología para la historia o el oficio del historiador, 1949]. Ambos historiadores, como es bien sabido fueron promotores de la Escuela Francesa de los Annales, escuela que iniciara un fructífero campo en los estudios históricos y una crítica seria a la historia como había venido desempeñándose, influida por las ideas positivistas de Auguste Comte.

Tanto Bloch como Febvre vivieron la crisis de la sociedad y del pensamiento occidental frente a las dos guerras mundiales. Antes de ellos, la historia de los hechos, los acontecimientos y los héroes: la historia del progreso, había dominado en la academia europea; ellos vivieron la destrucción de Europa, situación que planteaba la imperiosa necesidad de mirar al pasado desde una nueva

\footnotetext{
${ }^{2}$ La primera edición del libro de Bloch es de 1949; para 1979 se habían realizado diez reimpresiones. En México, el FCE lo publicó con el poco atinado título de Introducción a la Historia, tal vez los editores del Fondo pensaron que una apología no es algo importante. Sobre esta reflexión, sobre la historia, su método y su compromiso con su tiempo puede verse el prólogo de Felipe Ruiz Martín al libro de Fernand Braudel, La historia y las ciencias sociales (1989).

${ }^{3}$ Lucien Febvre escribió en 1952 el prólogo a su libro, en 1970 se realizó la primera edición en español que también fue seguida de numerosas reimpresiones.
}

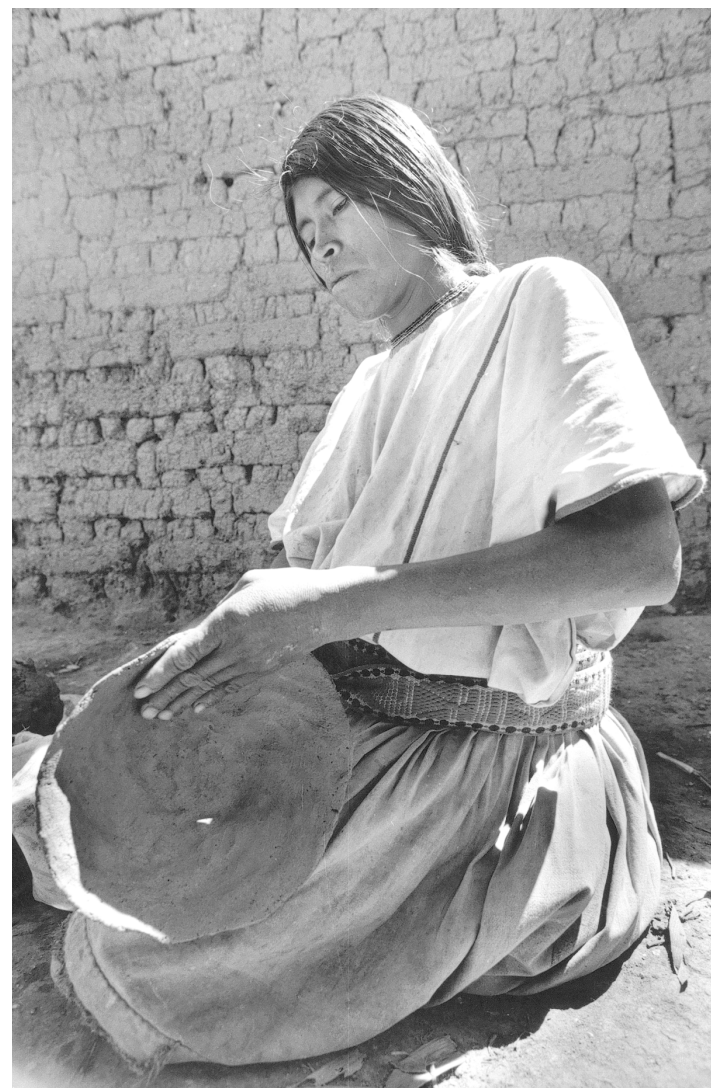

Espiritu Santo, Tamazulapan, Vittorio D’Onofri, 1996

óptica, desde una posición más crítica. Bloch y Febvre querían una historia comprometida, una historia que no marcara una división con las demás disciplinas sociales, sino que se nutriera de ellas y a la vez las alimentara y enriqueciera desde la ventaja que da el tiempo. De esta manera podrían entender mejor las complejidades del devenir humano.

En sus trabajos, Bloch y Febvre nos permitieron conocer sus preocupaciones como historiadores, sus compromisos marcados por su tiempo y por la materia de su oficio. Ambos cuestionaron la relación entre la historia, las ciencias sociales y los problemas de su sociedad y ambos hablaron también de los aspectos metodológicos que todo historiador debe resolver al situarse frente a las evidencias del pasado. Debemos recordar que eran medievalistas y que sus principales obras se refieren a aquellos 
distantes años, sin embargo, eso no los desvinculó de su momento histórico, por el contrario, creían que entender el origen del estado, las razones que guiaron a Lutero, la diversidad de la sociedad europea frente al pensamiento unificador del Vaticano eran, entre otros temas, importantes para entender a Europa y la crisis que vivía.

Se podrá argumentar que estos historiadores franceses no son los únicos que se han preocupado por su momento histórico. Es cierto, sin embargo, he querido traerlos a la discusión porque ejemplifican muy bien la posición que todo científico social debe tener. Una postura que combine un compromiso con su momento histórico, una postura analítica y crítica de su sociedad y sus antecedentes, y una práctica seria de la disciplina. El libro de Bloch es una constante consideración en la que se cruzan la discusión del status de la historia como disciplina científicamente construida, con una reflexión del método histórico y una crítica a la Europa de aquellos años.

Es imposible entender a Bloch y a Febvre y valorar adecuadamente sus aportes a la historia sin tomar en cuenta el momento en que vivieron. El primero escribió su libro en la prisión durante los años de la ocupación alemana en Francia, durante la segunda guerra mundial. Bloch era judío, formó parte de la resistencia, estuvo en prisión y fue fusilado. Nunca llegó a ver su libro Apologie... publicado, pero hoy nos inquieta pensar que él considerara importante escribir sobre la historia y su método en esos difíciles años. Si lo hizo fue porque creía que romper con la vieja tradición positivista que había privado en los estudios históricos podía aportar algo a la mejor comprensión del pasado de Europa y que esa comprensión era una crítica profunda de su presente.

Otros muchos autores han escrito sobre la historia desde una posición crítica, otros más sobre el método histórico, pero pocos han logrado un equilibrio entre sus compromisos políticos y el buen desarrollo de un método. Unos prefieren usar a la historia para cuestionar a la sociedad, pensemos en los historiadores influidos por el materialismo histórico. Ellos se preocupaban profundamente por las injusticias y las desigualdades de su sociedad y no obstante sus innegables aportes al mejor conocimiento del capitalismo y la situación de las clases trabajadoras, en muchos casos, su método fue empobrecedor y reduc- cionista, se cerraba a un diálogo fecundo con otras disciplinas y, en ocasiones, con la misma realidad. Otros historiadores, por el contrario, han elaborado importantes manuales referidos al método histórico pero han dejado de lado la reflexión filosófica sobre sus compromisos.

Si aquellos historiadores que nos antecedieron legaron a la posteridad sus inquietudes y sus reflexiones en importantes libros, por qué no hacerlo nosotros también, los etnohistoriadores, pero no en artículos breves como lo hemos hecho la mayoría de las veces, sino en obras que trasciendan nuestro tiempo. Porque a pesar de los importantes y muy numerosos libros escritos desde la óptica etnohistórica, aún falta una reflexión profunda sobre el método etnohistórico y sobre la forma como esta disciplina puede arrojar luz a la mejor comprensión del presente de los pueblos de tradición no occidental. ${ }^{4} \mathrm{De}-$ bemos desmenuzar analíticamente cada uno de los pasos de la famosa relación entre el método histórico y el antropológico, es intrascendente que sigamos repitiendo que etnohistoria es la antropología aplicada al pasado mientras no reflexionemos qué implica exactamente esta combinación. Porque, al fin y al cabo, sin un cuidadoso manejo de las fuentes históricas, sin nuevas preguntas que guíen nuestro camino por el bosque de los documentos, sin buenas técnicas de análisis, no hay buena etnohistoria. El método con el que nos aproximamos a los escritos antiguos debe de vivir en un constante enriquecimiento con nuevas aproximaciones desde el presente, con nuevas dudas, sin perder de vista el compromiso con la construcción de un mundo plural que viva en el respeto y no en la intolerancia, en la interrelación y no en el exclusivismo.

\footnotetext{
${ }^{4}$ En las últimas décadas del siglo XX, la relación entre la historia y el presente de los pueblos indígenas se vio influida por la simpatía que antropólogos y etnohistoriadores tenían por los indígenas con quienes trabajaban. A menudo cayeron en una simplificación de la historia y en idealizaciones que en nada ayudaron a la buena comprensión de la historia y de las raíces, muy complejas, de la situación presente. Un ejemplo concreto: en el estado de Oaxaca se dice que los problemas que las comunidades indígenas enfrentan entre sí por límites de tierras y las dificultades políticas a su interior se deben a las presiones de la sociedad externa, antes colonial y ahora neoliberal, cuando en realidad tienen su origen en un complejo entramado entre factores externos e internos.
} 
Nuestras búsquedas deben enriquecerse, alimentarse, con los escritos históricos, la literatura, la filosofía y los avances de las ciencias contemporáneas del mismo modo como Bloch, Febvre y sus seguidores, personas de la talla de Fernand Braudel, se nutrieron en las obras de Goethe, Pirenne, Durkheim, Michelet, Leibniz y muchos más. Ahora tenemos los trabajos de gente como Michael Foucault, Mijail Bajtín, Jack Goody, Hayden White, Isaiah Berlin y tantos otros pensadores de la segunda mitad del siglo XX, cuyas obras, en ocasiones difíciles de leer, son una guía en la búsqueda de un nuevo método que nos acerque a la cabal comprensión de que hay muchas maneras de pensar y de vivir, y que muchas veces nuestra propia manera de pensar y de ver el devenir histórico, la vida y las relaciones sociales, oscurecen nuestra visión de otras sociedades, ya sean distintas en cultura o en la misma tradición occidental pero distintas en tiempo. Tenemos la tarea pendiente de aprender de las filosofías de la posmodernidad una nueva manera de pensar y reflexionar, de buscar conocer el pensamiento y la filosofía de otros pueblos y después escribir una obra que rivalice con los escritos de los historiadores franceses de mediados del siglo XX. Una obra que combine nuestros compromisos políticos con un análisis serio y profundo del método etnohistórico.

\section{EN EL TERRENO DE LA ETNOHISTORIA}

Dentro de lo que podemos llamar etnohistoria hay libros que son un aporte al saber universal y al conocimiento de la humanidad en sus intrincadas relaciones étnicas, políticas, religiosas y económicas. Libros que rebasan el ámbito mesoamericano porque han tratado de descubrir a las sociedades nativas de Mesoamérica antes y después de su encuentro con occidente; se han esforzado

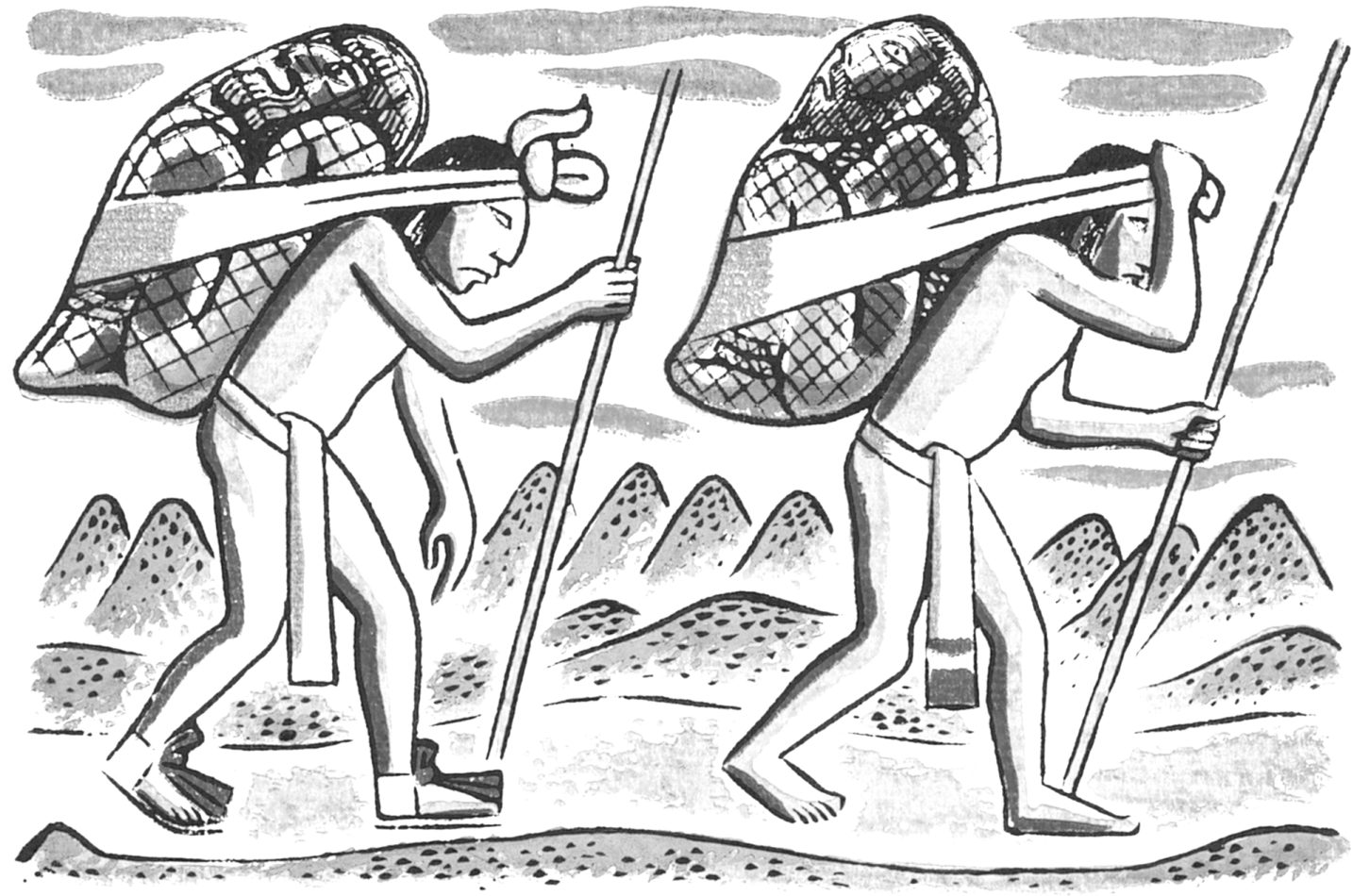

Miguel Covarrubias, 1942 
por comprender cómo se organizaba la sociedad nativa, cuál era su técnica y sus relaciones con su ambiente, cómo vivían y cómo pensaban aquellas personas antes de 1521 y después de esa fecha. Acá sólo quiero mencionar a mis favoritos, recordar por ejemplo a Ángel Palerm (1970, 1972 y 1973) y a Pedro Carrasco (1950, 1976 y 1996); los libros de Alfredo López Austin, en particular Hombre-Dios (1973) y Cuerpo humano e ideología (1980). Para las sociedades indígenas bajo el poder colonial, los libros de Charles Gibson y Nancy M. Farriss, desde mi punto de vista, son los clásicos entre los clásicos. El libro de Gibson, Tlaxcala en el siglo XVI (1952), recupera más la capacidad de respuesta de los indígenas que su obra magna, Los aztecas bajo el dominio español (1964). En ésta última, a pesar de estudiar con maestría la continuidad y las adaptaciones de la sociedad mexica, termina por mostrarla abatida, reducida al silencio y al final de todo al alcoholismo (1967: 413-418). El libro que en los últimos años ha tenido un fuerte impacto es el de Nancy M. Farriss (1984) sobre los mayas de Yucatán bajo el dominio colonial; lo más valioso del libro es el esfuerzo realizado por la autora para entender la lucha de los mayas para reconstituir el orden del cosmos en momentos en que eso era aparentemente imposible. Existen para México infinidad de libros que han realizado un esfuerzo para descubrir la voz indígena, trabajos como los innumerables de Miguel León Portilla, Luis Reyes, Serge Gruzinski, James Lockhart y otros más. No pretendo hacer una larga revisión bibliográfica, sino mencionar algunos de los trabajos que han destacado por el manejo de una técnica que saca de los papeles la capacidad de decisión de los pueblos nativos.

Lo importante desde mi punto de vista, pensando en los futuros etnohistoriadores, será, además de nutrirse de los aportes de estos trabajos, analizar y estudiar el método que los guió. No se trata de trasladar mecánicamente las conclusiones de cada uno de ellos a otras regiones y otros momentos, sino de estudiar su método, enriquecerlo e innovarlo con nuevos aportes y reflexiones. Porque el método con el que manejamos nuestros datos no es un paso en el proceso de investigar, es la investigación misma, es el corazón del trabajo del etnohistoriador y condiciona en gran parte sus resultados finales.

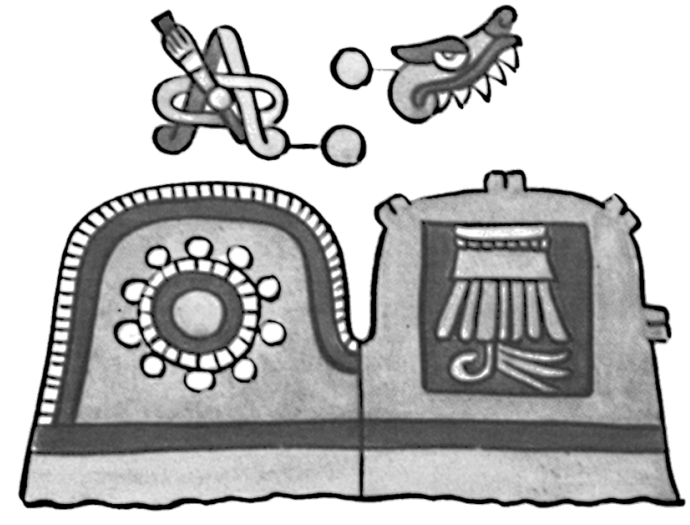

Códice Selden

El estudio del pasado se ha enriquecido conforme hemos sido más conscientes de que existen diferentes maneras de entender el mundo, su historia, sus sociedades, la vida y los hechos que la rodean. ${ }^{5}$ Esto debía de ser evidente, pues solemos decir que la etnohistoria es, precisamente, el estudio de las sociedades y su cultura, o con otras palabras: el estudio de las sociedades combinando técnicas históricas y antropológicas. Si consideramos que cultura es una forma de ver el mundo, de interpretarlo y vivirlo, entonces hacer etnohistoria por fuerza debería implicar entender al otro, su sociedad, su tiempo y su pensamiento, pero en la práctica no siempre es así. Existen colegas que continúan acercándose a los pueblos indígenas del pasado como si su pensamiento, su manera de interpretar su realidad y su contexto, fuera igual al nuestro. Como ejemplo de esta problemática debemos ver la reflexión contenida en el artículo de Federico Navarrete, "Las fuentes históricas más allá de la dicotomía entre historia y mito" (1999), sobre la forma como los historiadores concebimos la filosofía que guiaba la construcción de la historia mesoamericana. Para unos estudiosos, las fuentes históricas escritas por los indígenas contienen datos reales, sujetos a comprobación, a criterios de verdad (ibid: 231). Para estos colegas, los mesoamericanos entendían su historia, reconstruían su pasado y guardaban

\footnotetext{
${ }^{5}$ Varios autores contemporáneos se han ocupado de estudiar los procesos cognitivos de las sociedades; por ejemplo, Jack Goody (1990), todo el libro se ocupa de esta reflexión pero puede verse una afirmación interesante en la p. 36. Véase también Clifford Geertz (1983).
} 
su memoria en forma semejante a la nuestra, y cuando este criterio no corresponde con lo que encuentran en los códices o en los escritos alfabéticos de los indígenas los califican de falsos, como ha ocurrido con el grupo de códices Techialoyan. Para otros colegas, los mesoamericanos entendían la historia en términos míticos, con un contenido simbólico (ibidem). Como correctamente señala Federico Navarrete, no se trata de ver si los hechos históricos en las fuentes indígenas son reales o míticos, sino de entender cómo construyeron los mesoamericanos su historia, cómo explicaron el paso de los tiempos y la posición del género humano en ellos.

Puedo citar otro caso, pensar, por ejemplo, en los numerosos escritos que se han realizado sobre los códices prehispánicos y coloniales desde el escritorio y que no han considerado como algo central tratar de conocer a las personas cuyos antepasados escribieron esos códices. Los avances más notables en la comprensión de las páginas de los códices de tradición mesoamericana — prehispánicos y coloniales - se han logrado gracias a la combinación de trabajo en gabinete, con días agradables y en ocasiones difíciles, visitando y acercándonos a las personas que descienden de aquella tradición y que hoy la mantienen viva; claro, con los cambios que, en mayor o menor medida, afectan a cualquier sociedad. ${ }^{6}$

Descubrir el pensamiento ajeno encerrado en los glifos o en las letras no es fácil, por fuerza tratamos de entender al otro a partir de nuestros esquemas y conceptos mentales. Muchas veces lo que hacemos es hablar sobre los indígenas pero desde nuestro punto de vista, desde nuestros conceptos, desde nuestros prejuicios o nuestras idealizaciones. Romper este acercamiento construido desde una óptica para tratar de elaborar aproximaciones desde otros puntos de vista no es sencillo. Debemos concebir la pluralidad de las sociedades como un diamante formado por múltiples facetas que se unen y entrelazan formando al género humano. Describir otra sociedad y su cultura desde nuestro pensamiento sin hacer un esfuerzo por entender sus ideas, equivale a describir ese diamante como si fuera un triángulo. Es ne-

${ }^{6}$ Unos notables ejemplos son los trabajos de Maarten Jansen (s/f.), Carrera González y Geert Bastiaan Van Doesburg (1996), entre otros. cesario intentar conocer la forma ajena de leer la realidad, de entenderla y construirla. Desde mi punto de vista, los clásicos de la etnohistoria lo han sido porque se han esforzado por comprender a la otra sociedad, no sólo describir lo que a ella le ocurrió. Más bien, entender cómo esa sociedad vio lo que ocurrió en su historia, cómo influyó su pensamiento en sus decisiones, sus acciones y cómo todo se entretejió con la historia universal de su época. No pretendo, de ninguna manera, construir barreras infranqueables entre el pensamiento de los pueblos de tradición no occidental y nosotros, herederos lejanos de los griegos y los romanos. Hoy, más que nunca, hay que reforzar la unidad del género humano, entender nuestras analogías, nuestras semejanzas, porque si fuéramos tan diferentes no podríamos comunicarnos, sería imposible escribir la historia de otros pueblos distintos al nuestro. Es cierto que pueden haber malos entendidos, pero éstos se superan si hay voluntad de conocerse, de dialogar en la comprensión y el mutuo entendimiento (Villoro, 1989; Beuchot, 1997).

Si nos centramos en la investigación etnohistórica referida a los años coloniales de México, el trabajo futuro tiene un campo prometedor si trata de encontrar entre los miles de legajos surgidos del poder y la burocracia novohispana, la voz de los indígenas. Porque el pensamiento mesoamericano no desapareció con la conquista, como a menudo se cree, ni con el establecimiento del poder colonial, por el contrario, los indígenas con sus ideas explicaron esos sucesos y tomaron decisiones que influyeron en su futuro. La búsqueda de la visión indígena, de su voz, de su sentir, debe mantenerse frente a los códices y los lienzos, en los escritos en lenguas indígenas y en todos aquellos escritos que son fruto del encuentro entre Occidente y los pueblos nativos.

\section{ENTRE LOS ESCRITOSY LOS PAPELES}

Hacia 1970, estando en el exilio, el poeta uruguayo Mario Benedetti, escribió un poema que, por alguna razón extraña, me hace pensar en el impacto del mundo colonial novohispano sobre el mesoamericano. El poema se titula "Ceremonias" (1990), y uno de sus fragmentos dice: 


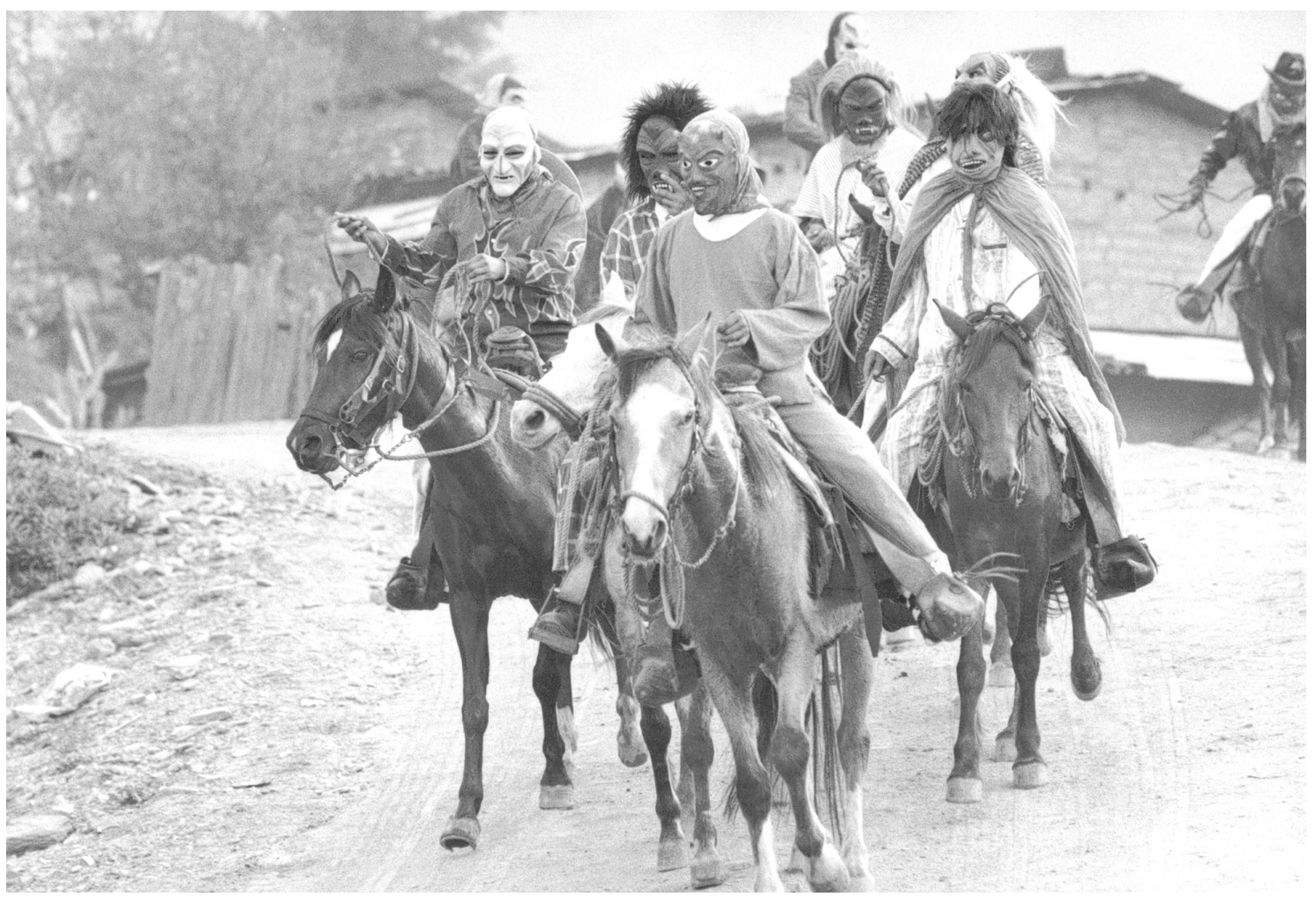

San Pedro Yolox, chinanteca, Vittorio D’Onofri, 1995

Pero una madrugada forzaron las puertas Nos allanaron el desván y la memoria Decidieron por nosotros en mitad de la duda Nos quitaron los fantasmas y los papeles Levantaron un cepo de palabras

Si pensamos en el mundo colonial, en el gobierno que se estableció sobre el antiguo orden mesoamericano, el poema parece cobrar vida. El mundo indígena quedó oculto entre papeles, entre procesos y palabras legales que se convirtieron en un verdadero instrumento de tortura para los naturales de esta tierra. La jerga legal, las palabras desconocidas que debían encabezar las solicitudes y demandas que los indígenas presentaban ante los jueces o tribunales fueron un cepo que los agobió y un poderoso elemento de cambio cultural.

Para los antropólogos y los etnohistoriadores es evidente que la sociedad indígena no desapareció con la conquista; basta visitar una comunidad cercana para escuchar un idioma mesoamericano, basta conversar con un anciano para reconocer las historias que explican las páginas de los códices. Pero aquellos estudiosos que no levantan la mirada del papel y no dirigen sus pasos más allá de su escritorio o del archivo, jamás reconocerán que los pueblos mesoamericanos continuaron reproduciendo su cultura en los siglos coloniales, sólo que sus ideas y su forma de vida están escondidas atrás de la palabrería legal de los documentos de la época. En una gran proporción, el trabajo del etnohistoriador y del historiador depende de documentos de carácter judicial, que evidentemente no son nuestras únicas fuentes. Podemos y debemos usar la arquitectura, la pintura, la escultura, la música, que son fuentes de información; también observar el paisaje, trabajar las cifras estadísticas, pero aun así debemos pasar horas leyendo formularios repetitivos e innumerables términos legales. 


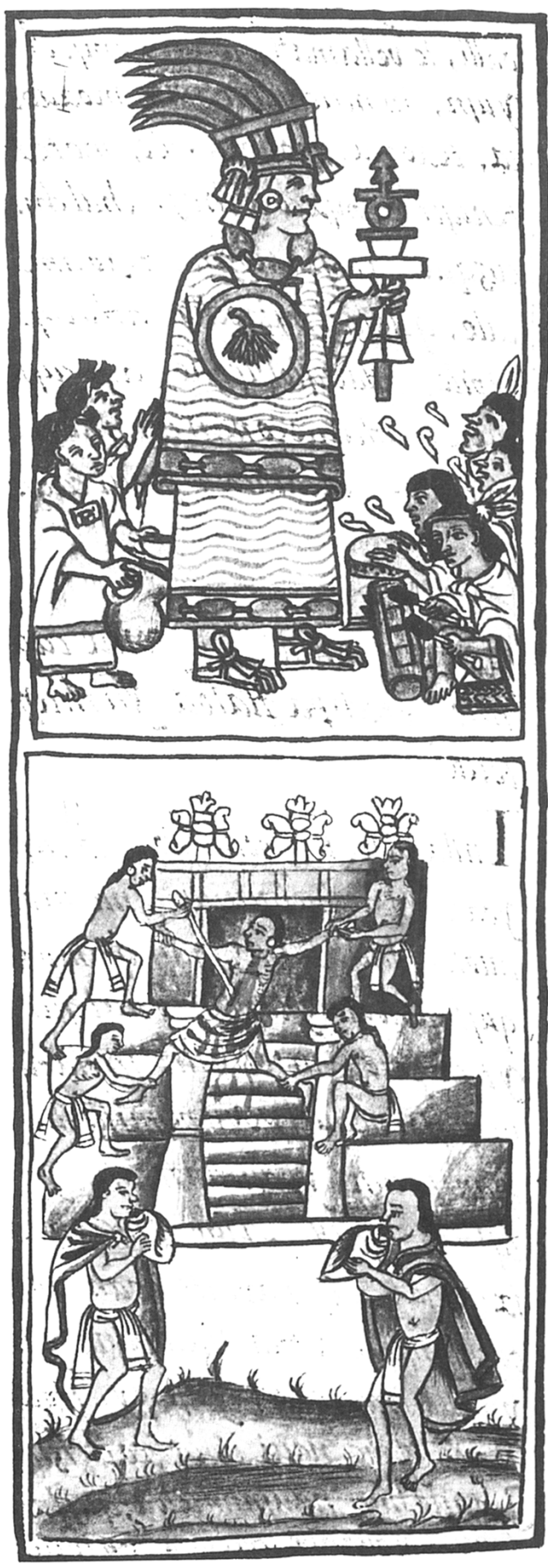

Chalchiuhtlicue; Códice Florentino
Los pasos de los procesos judiciales en los siglos XVI al XVIII, eran desconocidos por muchos de los mismos españoles y cuánto más por los indígenas. Debido a esto, las autoridades indígenas y todas las personas que presentaron una demanda o una solicitud ante la autoridad, en la mayoría de los casos, tuvieron que recurrir a un abogado o a un procurador. Además muchos no sabían escribir, tampoco hablar español, por eso existían escribanos e intérpretes españoles que tradujeron sus ideas y sus palabras a los términos que los jueces entendían y aceptaban. En esta manera su pensamiento fue ocultándose tras la traducción, tras los términos judiciales.

El pleno ejercicio del poder colonial no se logró sólo en las batallas, o en los esfuerzos de los frailes, fue dándose en los tribunales, en las leyes y la burocracia, con sus interminables e incomprensibles argumentos legales (Greenleaf, 1981; Borah, 1985; Kellogg, 1995; Ruiz Medrano, 2000). Los indígenas pocos años después de la guerra y con más vigor después de mediados del siglo XVI, abarrotaban las salas de la audiencia buscando solución a sus conflictos internos y a las numerosas dificultades ocasionadas por los españoles y por otros indígenas, pensar que lo hacían porque eran los vencidos es simplificar las razones que los guiaron. Las respuestas en la historia no son sencillas, lo que parece obvio no lo es, en especial cuando indagamos la confrontación entre mundos con filosofías y culturas diferentes. Es fácil probar que recurrieron a los jueces y a los tribunales, es difícil saber por qué lo hicieron, pero la respuesta debemos buscarla no sólo en la fuerza de las armas sino en las concepciones nativas del poder (Gruzinski, 1988; López Austin, 1989), en las dudas indígenas cuando se cuestionaron de dónde habían venido los españoles y en las respuestas que encontraron (Romero Frizzi, 1999).

Conforme los indígenas acudieron a los tribunales fueron ahogándose en un mundo que no comprendían plenamente, con un sentido de justicia diferente al suyo, con procesos, penas y concepciones legales también distintas, eso sin hablar de las diferencias contenidas en los idiomas que se enfrentaban en los procesos a través de traductores, intérpretes y escribanos; además cada idioma encerraba un pensamiento distinto aunque en continua interacción con el otro y con su entorno. Y si tomamos en 
cuenta otros factores que estuvieron presentes en los asuntos legales de los indígenas, como el paso de los argumentos indígenas (que ellos acostumbraban plasmar en pictografías) a la escritura alfabética, en procesos que tenían injerencia en una sociedad donde muy pocos sabían escribir y donde era importante la transmisión del conocimiento por medios orales como la recitación, el canto, el teatro y la danza, entonces, si pensamos todo esto, podemos imaginar la gran confusión que creó la confrontación entre la sociedad nativa y el poder legal

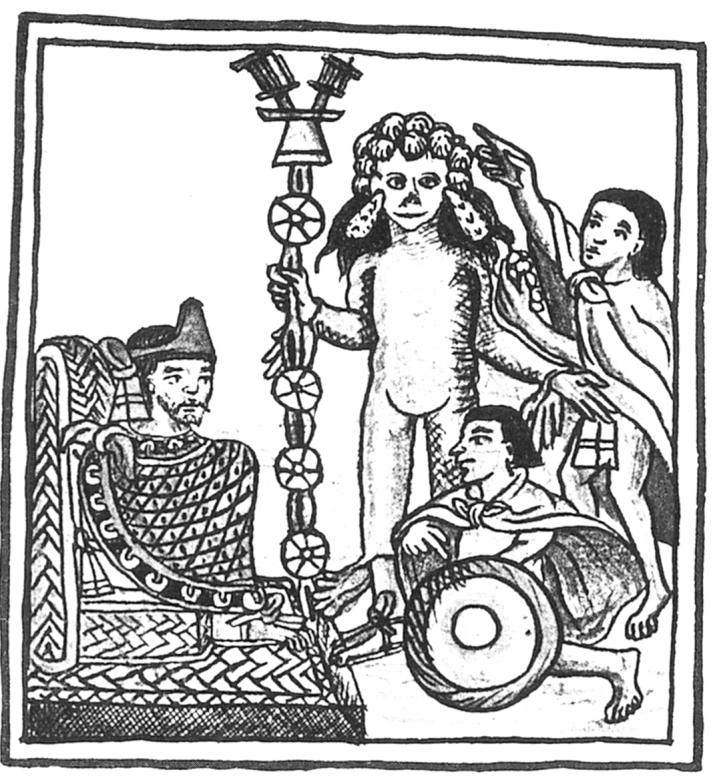

Preparando el sacrificio; Códice Florentino

novohispano. Esto también nos hace pensar que los documentos que tenemos en nuestras manos y en los que ponemos toda nuestra esperanza cuando escribimos nuestra versión de la historia, son apenas un pequeño pedazo de aquella inmensa realidad, la que debemos intuir e imaginar a través de minuciosos procedimientos de acercamiento al mundo de aquellos años.

El conocimiento de la sociedad nativa y la lectura casi entre líneas de los documentos buscando las ideas indígenas y sus sentires implica pasos sutiles, difíciles de describir; trataré de esbozarlos. El primero y tal vez el más obvio es sencillamente conocer a los descendientes contemporáneos de aquellos pueblos de antaño. El trabajo de campo en la etnohistoria no es un paso evitable en el proceso de conocer, es central; no se trata de visitar una comunidad y describir lo que vemos, se trata de ir más allá, de esforzarnos por entender a las personas y su lógica, su manera de pensar y su modo de organizarse o simplemente de vivir la vida. Indudablemente que el tiempo ha pasado, pero, en contra de lo que algunos piensan, mucho podemos conocer actualmente de aquel pensamiento antiguo. Nuestro trabajo también puede enriquecerse y mucho con la lectura de trabajos etnográficos sobre las personas cuya historia nos inquieta. Del presente y del conocimiento etnográfico debemos marchar cuidadosamente hacia el pasado, hacia los textos de los cronistas, los escritos en lenguas indígenas y las páginas de los códices; finalmente volveremos a los expedientes legales con más sensibilidad para descubrir entre su palabrería y formularios legales, las intensiones ocultas de los indígenas. ${ }^{7}$

Otro paso más, evidentemente, es el estudio del idioma de las personas cuyo pasado queremos conocer, pensando que el idioma contiene no sólo el pensamiento indígena, sino su pensamiento en constante interacción con el mundo que lo rodea. Afortunadamente los sabios indígenas escribieron su visión de la historia, lo hicieron en su propio sistema de escritura, con sus pictografías, y también con el alfabeto. Por eso tenemos cientos de códices que los pueblos de tradición mesoamericana realizaron en el curso del mundo colonial para preservar su manera de pensar, para adecuar las antiguas razones al presente y también para hacer saber a los españoles sus preocupaciones centrales. En esos intentos la escritura antigua fue conviviendo con los escritos alfabéticos realizados por los nobles indígenas cuando aprendieron a escribir con el alfabeto latino a través de su relación con los frailes, los curas y los miembros de la burocracia. Generaron códices en técnicas mixtas que son la mejor prueba de aquellos mundos en contacto, obras que combinaban las letras y los pictogramas como La historia

${ }^{7}$ Sobre el método de intertextualidad, puede verse Todorov (1988: cap. V). Sobre su aplicación en los documentos coloniales, Farriss (1989). 
tolteca chichimeca (nahua), el Códice Sierra (chocholteco de Tejupan, Oaxaca), el Lienzo de San Miguel Tequicistepeque (chocholteco de Oaxaca), el Lienzo de Tiltepec (zapoteco de la sierra) y muchos más. Respecto al alfabeto, del centro de México tenemos infinidad de textos escritos en náhuatl, que han sido materia de innumerables libros que nos han permitido conocer ese mundo en su pasado prehispánico y en sus cambios coloniales. Sabemos también de los mayas con sus notables libros: los libros del Chilam Balam y el Popol Vuh, los Anales de los cakchiqueles, entre otros escritos de ese pueblo. Tenemos además de los cantos y las historias escritas por los nahuas y los mayas, textos en mixteco, zapoteco, p'urhépecha, chontal de Tabasco, naua de Oaxaca y Guerrero, kiche, chocholteco, y conforme avanzamos en la investigación nuevos escritos van apareciendo mostrando una incréble literatura indígena que no habíamos imaginado. ${ }^{8}$

Algunos de estos documentos fueron presentados ante las autoridades novohispanas como prueba de una parte involucrada en un conflicto, es difícil saber qué entendieron los abogados de la audiencia cuando vieron los códices y los lienzos, o alguien les tradujo un texto en idioma indígena. Es posible pensar que los nobles indígenas que acudieron a los tribunales a presentar sus demandas portando sus códices pintados y sus lienzos fueron testigos

\footnotetext{
${ }^{8}$ Ejemplos de los textos escritos en sus idiomas por los indígenas pueden verse en los apéndices documentales de varios de los volúmenes que integran la colección Historia de los pueblos indígenas de México, coordinada por Teresa Rojas y Mario Humberto Ruz, por ejemplo: La genealogía de los señores chontales, escrita en 1576 en chontal (Ruz, 1994: 281-287); Título de Tanjoveltic, 1560; Mandamiento en náhuatl, Chiapas (De Vos, 1994: 207-208, 212-213); Composición de tierras de Ixcateopan, Guerrero, 1712, en náhuatl; Adivinación con maíz, siglo XVII, náhuatl de Guerrero (Dehouve, 1994: 188 y 195); Conflicto por tierras entre comunidades, maya de Yucatán (Quezada, 1997: 235-236). Numerosos documentos escritos en zapoteco, mixteco, chocholteco y náhuatl existen en el ramo de Tierras del AGN, y en el Archivo del Poder Judicial de Oaxaca. Oudijk (2000) y Romero Frizzi (2000) han localizado varios documentos en zapoteco. Documentos escritos en chocholteco, Oaxaca, han sido localizados en los archivos municipales por Geert Bastian van Doesburg, en un proyecto actualmente en curso. James Lockhart lleva años trabajando sobre los nahuas a través de sus documentos (1992). Kevin Terraciano basa su libro en la traducción de numerosos textos en mixteco, de Oaxaca (en prensa); Terraciano y Sousa (1992) han traducido documentos en mixteco y náhuatl de Oaxaca (manuscrito en preparación). La revista Estudios de Cultura Náhuatl también ha publicado numerosos documentos en distintas lenguas indígenas.
}

de las dificultades de la traducción, vieron cómo lo que ellos argumentaban era vertido al alfabeto, que lo que explicaban en su idioma era traducido al castellano y convertido en argumentos legales. ${ }^{9}$ Ante esa realidad, un doble lenguaje debió producirse en los pueblos: uno hacia el interior de su comunidad para preservar lo que les era propio, lo que era sagrado e importante, como sus calendarios y libros sagrados, los títulos de sus tierras y sus historias de origen. Otro en su relación con los poderes novohispanos, como las solicitudes de mercedes, títulos de composición, demandas por conflictos en las elecciones de las autoridades de los cabildos, o por límites de tierras con el poblado vecino. Entre ambos no existió una barrera infranqueable, los documentos cruzaron de un mundo al otro produciendo un diálogo confuso (Todorov, 1988; White, 1992), y al final, a través del discurso escrito y legal, un proceso de cambio afectó prácticamente todos los ámbitos de la vida indígena, como su relación con la tierra, su concepción del espacio y del poder, la relación con los poblados cercanos, el sistema de parentesco, su identidad (Kellogg, 1995). En diálogos que no se han conservado pero que seguramente tuvieron lugar antes y durante cada proceso legal que involucró indígenas, se fue dando una traducción de unos principios legales a otros. Las autoridades indígenas se dieron cuenta del poder del alfabeto y fueron traduciendo sus códices antiguos a documentos escritos con letras, se fue creando un nuevo género de documentos que combinaban las razones indígenas, su concepción del tiempo, del espacio y de la historia con términos legales españoles y con una nueva visión de la realidad que los nobles nativos iban forjando. Estos documentos cumplían al interior de los pueblos la misma función que los códices antiguos, mantener su historia, definir su tierra

\footnotetext{
${ }^{9}$ Existe evidencia de que en muchos tratos entre conquistadores y señores indígenas, estos últimos presentaban sus lienzos pintados como prueba. Puede verse: Queja de los principales de Uchichila sobre lo que le habian traído al Lic. Albares de Castañeda, corregidor de la ciudad, todo lo cual trajeron pintado en dos mantas y la pintura fue declarada por lenguas de intérpretes que estuvieron presentes [1533], AGI, México, 68. El alcalde mayor de Teposcolula (Mixteca, Oaxaca) le pidió al cacique de Yanhuitlán que presentara la memoria de sus tierras, el cacique trajo una pintura. La pintura fue traducida por el intérprete de mexicano a español [1567], AGN, Tierras, 985: 2
} 


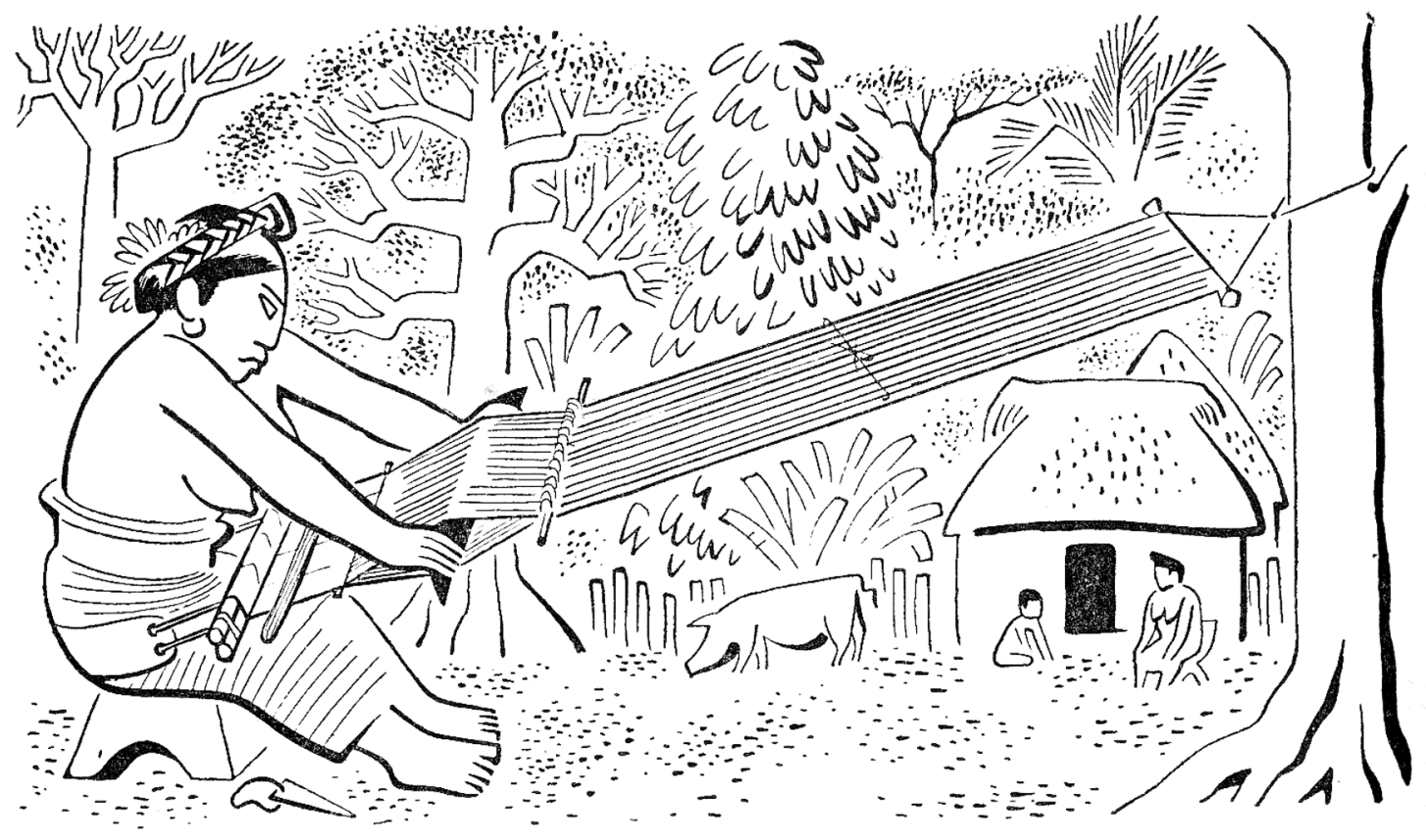

Mujer de Cosoleacaque; Miguel Covarrubias, 1947

con sus linderos, legitimar a sus gobernantes, conservar la memoria de la fundación del reino (altepetl en náhuatl, yetze en zapoteco, ñuu en mixteco, etcétera) y la construcción de su templo. Unos textos fueron escritos totalmente con letras, como la Memoria del pueblo de Juquila en la sierra zapoteca de Oaxaca (Romero Frizzi, 2000); el Lienzo de Tabaá, también en la sierra, estuvo formado por un lienzo que a la vez era genealogía y mapa y un escrito alfabético (Oudijk, 200o). En otros casos realizaron códices con figuras humanas muy influenciadas por la concepción española, como en el grupo de códices llamados Techialoyan (Galarza, 1980; Robertson, 1975: 253; Noguez, 1992: 8-13; Béligan, 1993). A todos estos documentos se les llamó en el siglo XX, a raíz de la reforma agraria, Títulos primordiales.

Los Títulos primordiales son uno de los mejores ejemplos que tenemos para mostrar las dificultades que entraña entender otra manera de pensar, así mismo son prueba de los tremendos errores que los historiadores podemos cometer cuando nos acercamos a la historia de pueblos con mentalidad distinta a la nuestra. Por unos años, los historiadores tacharon a los Títulos de viles falsificaciones, de falta de historicidad, todavía hoy varios historiadores piensan así, pero, poco a poco, a través de décadas de trabajo, desde 1970 aproximadamente, nos hemos ido acercando paulatinamente a la idea que originalmente debió guiar a sus autores (Gruzinski, 1991; Wood, 1998; Florescano, en preparación). ${ }^{10}$ Los Títulos son muy extraños, como dijera Serge Gruzinski; parecen falsificaciones, desde nuestro punto de vista consignan hechos históricos inexactos o inventados totalmente, no siguen un orden lógico, incurren en errores, dan fechas de fundaciones de pueblos imposibles, como 1521, 1523 y otras cercanas (Gruzinski, 1991: 105; Romero Frizzi, 1999; Terraciano, 2000; Terraciano y Sousa, 1992). Sin embargo, ellos contienen la forma mesoamericana de entender la historia, pero es una forma que a la vez muestra cómo la concepción del tiempo, del espacio y del poder de la

\footnotetext{
${ }^{10}$ Veáse el comentario sobre este problema en Menegus, 1989: 214,
} notas 14 y 15 . 
sociedad indígena fue cambiando en el contacto con el español y su empeño por organizar la política de los pueblos, su tierra, su religión, toda su vida.

Los Títulos son una nueva puerta que nos permitirá adentrarnos en la vida indígena de la época colonial, sus potencialidades para una versión nueva de la historia son infinitas por la gran variedad de Títulos que existen, por la mezcla en sus estilos: en códices tradicionales, en lienzos de increíble calidad artística o de pobre manufactura, en códices de estilo mixto: pintura y glosas, o en alfabeto y en muy distintas lenguas mesoamericanas. Podríamos pensar, por ejemplo, que un Título escrito totalmente con el alfabeto y en zapoteco presenta un mayor grado de occidentalización que uno realizado en un estilo mixto de pictografías y alfabeto, pero no es así. $L a$ Memoria de Juquila, poblado zapoteco serrano, parece contener los cantos o las recitaciones antiguas, en cambio, los códices del grupo Techialoyan muestran en sus figu- ras humanas nuevas concepciones de carácter más occidental. El análisis y estudio de cada uno de los detalles de los Títulos, relacionando su forma y su contenido, estudiando el idioma en que fueron escritos, la vinculación con su contexto, mostrarán nuevos procesos de cambio social y cultural, sobre todo lo mostrará desde el punto de vista indígena.

A través de los Títulos nos hemos dado cuenta de lo que preocupaba profundamente a los pueblos indios: la fundación de su pueblo y de su templo, la confirmación de su tierra, la demarcación de sus linderos y el derecho de sus señores a gobernar, pero contienen información de infinidad de temas como la identidad local, la visión de los extraños, las migraciones, el concepto de poder, entre otros. El análisis comparativo de los Títulos arrojará una nueva versión de la historia y además su estudio enriquecerá otros campos de la ciencia como la lingüística. Su estudio permitirá entender mejor los procesos de frag-

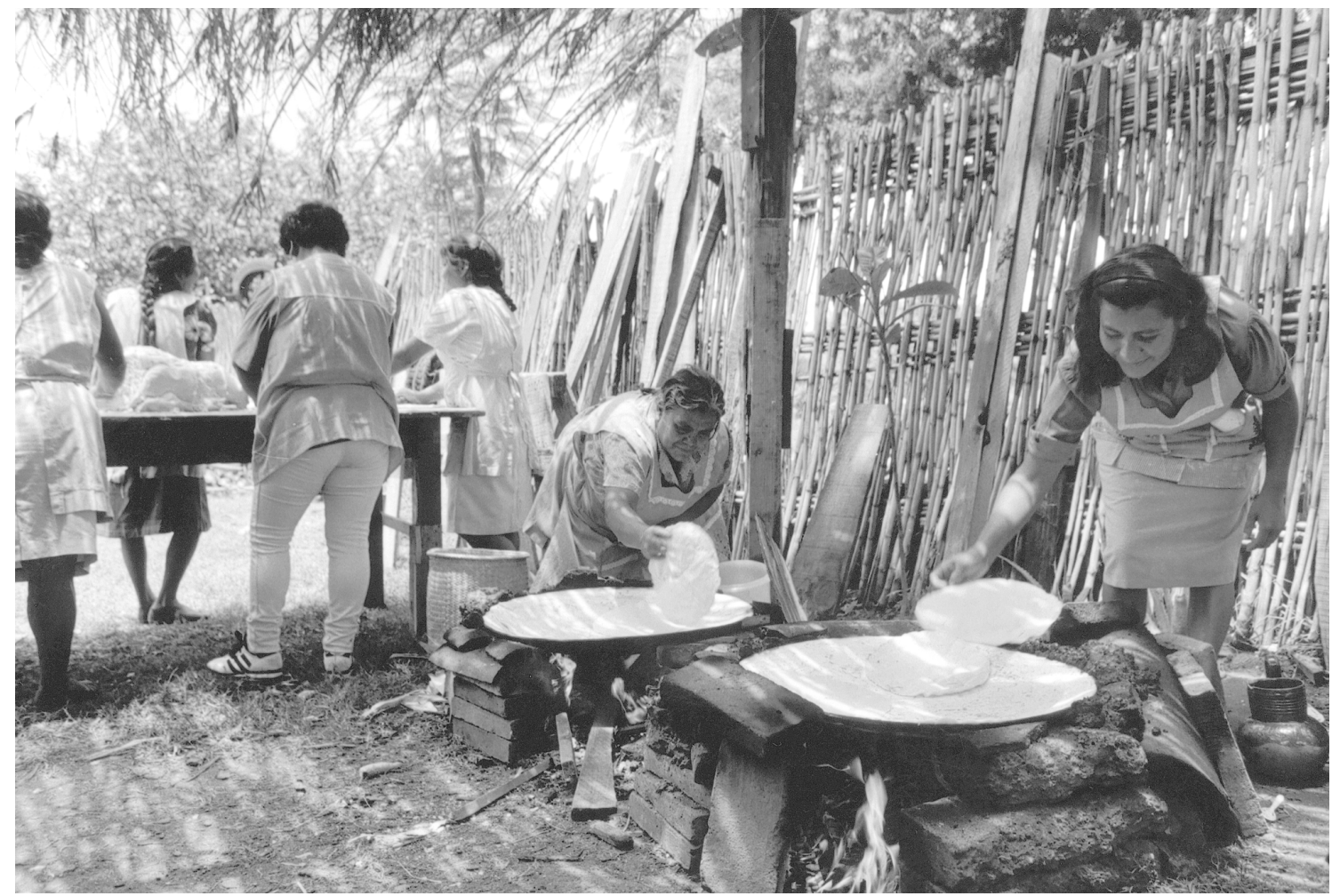

San Juan Teitipac, zapoteca del Valle, Vittorio D’Onofri, 1995 
mentación lingüística y niveles de inteligibilidad existente entre las localidades indígenas dentro de una misma familia lingüística, como por ejemplo el mixteco, el zapoteco, el chocholteco en el estado de Oaxaca, pero lo mismo se puede realizar en otras regiones.

El estudio del idioma en estos documentos será como una puerta hacia la mente de sus creadores. Aunque hay que tener presente que el lenguaje es un ser vivo y refleja los cambios que sus portadores vivieron. El estudio debe mantenerse abierto a la comprensión de múltiples procesos de cambios en diferentes regiones de la Nueva España, en los valles fértiles acosados por las haciendas o en las serranías inhóspitas, sujetas o no a los procesos de las congregaciones, y víctimas del repartimiento de los alcaldes mayores. Todos estos campos, apenas explorados por la investigación, se han abierto porque cambiamos nuestra manera de pensar, porque dejamos de ver a estos documentos como simples falsificaciones, para tratar de entenderlos en su propia lógica. El cuestionamiento de las fuentes no termina acá, hay que tener en cuenta que si las ideas y las decisiones indígenas estuvieron presentes en estos documentos salidos de la mano del anónimo escribano indígena, ¿qué no estarían presentes también?, sólo que más ocultas, en todos los documentos en que ellos se vieron involucrados, como las mercedes reales de sitios de tierra, las composiciones, las compras de tierra, los testamentos y los largos expedientes del ramo de Tierras, para citar un ejemplo. Porque las palabras indias no se conservaron únicamente en aquellos documentos en los que vertieron las ideas de los códices, también debieron de impulsar la escritura de documentos que encierran una apariencia muy fuerte de hispanidad.

Al menos, metodológicamente debemos cuidarnos de los terrenos llanos y firmes porque pueden ocultar áreas resbaladizas. Porque la ciencia, en este caso la etnohistoria, es una constante pregunta, una eterna búsqueda. Al menos debemos de preguntarnos si los documentos legales que parecen cumplir a la letra el espíritu de la ley española no eran usados y manipulados por las autoridades indígenas para sus propios intereses. Quisiera mencionar aquí un ejemplo. Está actualmente en marcha y se trata del proyecto de tesis de Alonso Barros sobre los conflictos por la tierra y el uso del derecho colonial y nacional en la zona baja de los mixes, en el Istmo de Tehuantepec. ${ }^{11}$ Alonso Barros propone (a través de trabajo de archivo, numerosas visitas a la región y conversaciones con ancianos y autoridades mixes) que cuando un conflicto por la tierra surge entre dos comunidades vecinas, las autoridades echan mano de todos los recursos a su alcance, desde la manipulación de fuerzas sagradas como la lucha entre nahuales, la aplicación de su sistema legal consuetudinario, y el uso de las leyes nacionales. Para las comunidades indígenas las resoluciones legales de los tribunales son hoy en día un arma para defender su tierra, junto con las luchas entre sus nahuales. Si esto ocurre actualmente, cuánto no sería en la época colonial, sólo que continuamos leyendo los expedientes únicamente desde nuestra óptica occidental y cuando por nuestra vista cruza un destello mesoamericano no lo vemos. Por ejemplo, en los expedientes legales, los nahuales aparecen veladamente como el rayo que incendió el templo enemigo, y el rayo es el más poderoso sobrenatural. Y los innumerables documentos legales que se acumulan en los tribunales formando pilas inmensas imposibles de leer en su totalidad son la prueba de esa lucha constante, de ese esfuerzo por tener un arma más, pero no la última, por defender su tierra. Frecuentemente leer cada uno de los expedientes por tierras nos cansa y nos confunde, no podemos descubrir la lógica interna, pero siempre hay que buscarla, hay que descubrir la otra mirada de la realidad.

\section{CONSIDERACIONES FINALES}

En una ocasión Lucien Febvre escribió: Concluir es detenerse. Por eso creo que este breve ensayo no debe llevar una conclusión, la reflexión sobre la etnohistoria y su método debe continuar. Pero sí quiero terminar con unas reflexiones. Si recordamos bien, al inicio de este trabajo dije que hablaría de la diferencia entre la historia y la etnohistoria como si fuera clara y nítida, como si ambas

\footnotetext{
${ }^{11}$ La tesis de doctorado actualmente en proceso de redacción se titula Alonso Barros van Hövell, Negotiating Rules: Territorial Dynamics in the Mixe Isthmus, Departamento de Antropología, Universidad de Cambridge, Reino Unido.
} 
fueran disciplinas diferentes y existieran dos campos de estudio. Ahora volveré sobre esta separación que era sólo operativa. Es cierto que quienes nos pensamos etnohistoriadores nos sentimos diferentes, podríamos decir que tenemos una identidad propia que nace de nuestra formación antropológica y de nuestra cercanía con los pueblos indígenas contemporáneos. Es verdad que muchos historiadores difícilmente penetran en la sierra y duermen en un petate buscando otra manera de pensar, pero afortunadamente sí hay quienes lo hacen, entonces la barrera se vuelve confusa.

Querer marcar una línea precisa entre historia y etnohistoria no es adecuado, la realidad presente y pasada es compleja y debemos emplear métodos complejos - nutridos por innumerables ciencias - para entenderla (Morin, 2000). Por fuerza, el método que trata de entender el pasado de los pueblos de tradición diferente a la del historiador que escribe debe de ser más complejo de aquel que estudia a su propio pueblo, pero todas las aproximaciones al pasado conforman la historia. Entenderemos mejor estas ideas, si sacamos la discusión sobre historia y etnohistoria del ámbito mesoamericano y la colocamos en un plano mundial, entonces la separación entre ambas se vuelve aún más difusa. Trataré de explicarme: la historia como nosotros la practicamos proviene de la tradición occidental, es fruto de la ilustración, del racionalismo, del pensamiento europeo, es heredera de pensadores como Descartes (siglo XVII) y de otros muchos que vivieron después de él, pero Occidente es sólo una pequeña parte del mundo, de un mundo plural e inmenso. Pensemos en África negra y árabe, en Oceanía, en el lejano Oriente y sus innumerables pueblos y culturas, en los quechuas, los aymaras y todos los demás de América del Sur; ni siquiera Europa es homogénea o, ¿qué ya olvidamos a los vascos, a los católicos y a los protestantes, a los irlandeses y a los gitanos? Entonces resulta difícil decir que la historia es la gran ciencia del pasado y la etnohistoria es la rama de aquella que se especializa en conocer, no sólo la tradición mesoamericana, sino todas las tradiciones de la humanidad. Si pensamos así, los papeles parecen invertirse, pero no creo que convenga romper la tradición. La historia debe de seguir siendo el estudio de todos los pueblos del mundo y la etnohistoria

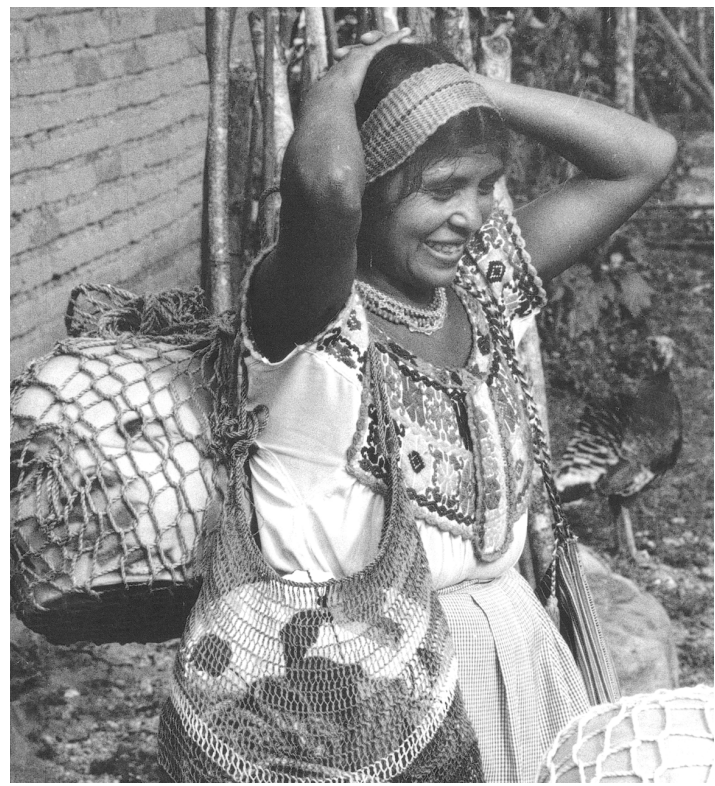

San Miguel Panixtlahuaca, chatina, Vittorio D’Onofri, 1995

es el método que nos permite entender la riqueza y la pluralidad del género humano. Como dijera Lucien Febvre, no hay una historia social, ni una historia económica, hay una historia de la humanidad.

Para terminar quisiera recordar las palabras de Marshall Sahlins contenidas en las conclusiones de un trabajo que publicó en 1983. Hablaba precisamente de la historia del pueblo maorí, de Nueva Zelanda, y de cómo, para tratar de entenderla, las aproximaciones de los antropólogos tenían que acercarse a las de los historiadores y viceversa. En ese contexto escribió:

De aquí en adelante la oscura historia de unas islas remotas merece un lugar al lado del autocomplaciente pasado europeo... por sus importantes contribuciones al conocimiento histórico.

La historia de la humanidad ha sido construida por todos los pueblos, por los habitantes de unas pequeñas islas en el Pacífico, por los pueblos mesoamericanos, por los quechuas, los mayas, los europeos y todos los demás. Entre todos hemos forjado la historia, en sus logros y en sus dramas: para entenderla, para conocerla en su diversidad, necesitamos técnicas sutiles e imaginativas. En esta búsqueda se ubica la etnohistoria. 


\section{Bibliografía}

Anderson, Arthur J.O., Frances Berdan y James Lockhart, 1976, Beyond the Codices. The Nahua View of Colonial Mexico, UCLA, Latin American Center, University of California Press, Berkeley.

Axtell, James, 1979, "Ethnohistory: an Historian's Viewpoint", en Etnohistory, vol. 26, núm. 1, pp. 1-13, invierno.

Béligan, Nadine, 1993, Códice de San Antonio Techialoyan. A 701. Manuscrito pictográfico de San Antonio de la Isla, Estado de México, Instituto Mexiquense de la Cultura, México.

Beuchot, Mauricio, 1997, Tratado de hermenéutica analógi$c a$, UNAM, Facultad de Filosofía y Letras, México.

Bloch, Marc, 1996, [1952, 1a. ed.], Introducción a la historia, Breviario núm. 64, FCE, México.

- 1996, Apología para la historia o el oficio de historiador, ed. crítica preparada por Étienne Bloch, FCE, México.

Borah, Woodrow, 1985, El Juzgado General de Indios en la Nueva España, FCE, México.

Carrasco, Pedro, 1950, Los otomies: cultura e historia prehispánica de los pueblos mesoamericanos de habla otomiana, UNAM, Instituto de Historia,INAH, México.

_ et al., 1976, Estratificación social en la Mesoamérica prehispánica, CISINAH, Nueva Imagen, México.

_-1996, Estudio político territorial del imperio tenochca. La Triple Alianza de Tenochtitlan, Tetzcoco y Tlacopan, El Colegio de México, Fideicomiso Historia de las Américas, FCE, México.

Carrera González, Florencio y Geert Bastiaan Van Doesburg, 1996, "Contribución sobre el calendario agrícola mazateco", en Anders Ferdinand, Luis Reyes García y Maarten Jansen, Códice Ixtlilxochitl: apuntaciones y pinturas de un historiador, Akademische Druck und Verlagsanstalt y FCE, México.

Cohn, Bernard S., 1975, "Etnohistoria”, en Davil L. Sills, Enciclopedia de las Ciencias Sociales, vol. 5, pp. 418-425, Ediciones Aguilar, Bilbao, España.

De Rojas, José Luis, 1989, "Tendencias de la etnohistoria en el México central”, en Revista de Indias, vol. XLIX, núm. 185, pp. 195-202.

De Vos, Jan, 1994, Vivir en frontera. La experiencia de los indios de Chiapas, Teresa Rojas y Mario H. Ruz, directores de la colección Historia de los pueblos indígenas de México, CIESAS, INI, México.

Dehouve, Danièle, 1994, Entre el caimán y el jaguar. Los pueblos indios de Guerrero, Teresa Rojas y Mario H. Ruz directores de la colección Historia de los pueblos indígenas de México, CIESAS, IVI, México.

Farriss, Nancy M., 1984, Maya Society under Colonial Rule. The Collective Enterprise of Survival, Princeton University Press.
__ 1989, "Idolatrías: antiguas y modernas", conferencia presentada en el Primer Congreso Internacional de Estudios Mayas, San Cristóbal las Casas, Chiapas, 14 de agosto de 1989.

Fevbre, Lucien, 1993, [1a. ed. 1970], Combates por la historia, Ariel, México.

Florescano, Enrique, s.f., "El canon memorioso forjado por los Títulos Primordiales”, capítulo del libro en preparación: Los cánones históricos.

Foucault, Michel, 1990, La verdad y las formas jurídicas, Gedisa Mexicana, México.

Galarza, Joaquín, 1980, Codex de Zempoala Techialoyan E 705. Manuscrit Pictographique de Zempoala, Hidalgo, Mexique, México, Mission Archeologique et Etnologique française au Mexique, col. Etudes Mesoamericaines, 7.

Geertz, Clifford, 1983, Local Knowledge. Further Essays in Interpretive Anthropology, Basic Books, Harper and Collins Publishers, Estados Unidos.

Gibson, Charles, 1952 [1a. ed. en inglés], 1991, Tlaxcala en el siglo XVI, Gobierno del estado de Tlaxcala, FCE, México.

_ 1964 [1a. ed. en inglés], 1967, Los aztecas bajo el dominio español (1519-1810), Siglo XXI Editores, México.

Goody, Jack, 1990 [1977], The Domestication of the Savage Mind, Cambridge University Press, Nueva York.

Greenleaf, Richard E., 1981, La Inquisición en Nueva España, FCE, México.

Gruzinski, Serge, 1988, El poder sin límites. Cuatro respuestas indígenas a la dominación española, col. Biblioteca del INAH, INAH, Instituto Francés de América Latina, México.

—_, 1991, La colonización de lo imaginario. Sociedades indígenas y occidentalización en el México español. Siglos XVI-XVII, FCE, México.

Harvey, H.R. y Hanns J. Prem, 1983, Explorations in Etnohistory. Indians of Central Mexico in the Sixteenth Century, University of New Mexico Press, Alburquerque.

Jansen, Maarten, s/f., Huisi Tacu. Estudio interpretativo de un libro mixteco antiguo: Codex Vindobonensis Mexicanus I, Centro de Estudios y Documentación Latinoamericanos, Incidentele Publicaties 24, Amsterdam.

Kellogg, Susan, 1995, Law and the Transformation of Aztec Culture, 1500-1700, University of Oklahoma Press, Norman and London.

LeGoff, Jacques, 1983, "Hacia una antropología histórica", en Tiempo, trabajo, cultura en el Occidente medieval, pp. 315-327, Taurus Editores, Madrid.

Lockhart, James, 1992, The Nahuas after the Conquest. A Social and Cultural History of the Indians of Central Mexico, Sixteenth Through Eighteenth Centuries, Stanford University Press, Stanford, California. 
López Austin, Alfredo, 1973, Hombre-Dios, religión y politica en el mundo náhuatl, UNAM, México.

- 1980, Cuerpo humano e ideología. Las concepciones de los antiguos nahuas, UNAM, México.

Martínez Marín, Carlos, 1976, "La etnohistoria: un intento de explicación”, en Anales de Antropología, pp. 39-63, vol. XIII, México.

Menegus, Margarita, 1989, "Los títulos primordiales de los pueblos de indios", en Sumario, Universidad de Valencia, Facultad de Geografía e Historia, España.

Morin, Edgar, 2000 [1994], Introducción al pensamiento complejo, Gedisa Editorial, Barcelona.

Navarrete, Federico, 1997, "Las fuentes históricas más allá de la dicotomía entre historia y mito", en Estudios de Cultura Náhuatl, vol. 30, pp. 231-256, UNAM, México.

Noguez, Xavier, 1992, “El grupo de códices Techialoyan”, en Códice Techialoyan García Granados, El Colegio Mexiquense, Gobierno del Estado de México, Toluca, México.

Oudijk, Michel, 2000, Historiography of the Benizaa. The postclassica and early colonial periods (1500-1600 A.D), Research School of Asian, African, and Ameridiand Studies, Universidad de Leiden, Holanda.

Palerm, Ángel, 1970, Agricultura y sociedad en Mesoamérica, col. Sep Setentas, 55, SEP, Diana, México.

— 1972, Agricultura y civilización en Mesoamérica, SEP, Diana, México.

__ 1973, Obras hidráulicas prehispánicas en el sistema lacustre del Valle de México, INAH, México.

Quezada, Sergio, 1997, Los pies de la república. Los indios peninsulares: 1550-1750, Teresa Rojas y Mario H. Ruz, directores de la colección Historia de los pueblos indígenas de México, CIESAS, INI, México.

Robertson, Donald, 1975, "Techialoyan Manuscripts and Paintings, with a catalog", en Handbook of Middle American Indians, pp. 253-280, vol. 14, University of Texas Press, Austin, Texas.

Rojas Rabiela, Teresa et al., 1982, "Algunas consideraciones sobre el quehacer de la etnohistoria en México", en Anuario Antropológico, pp. 203-209, 80, UNAM, México.

Romero Frizzi, María de los Ángeles, 1994, "Reflexionando una vez más: la etnohistoria y la época colonial”, en $\mathrm{Di}$ mensión Antropológica, pp. 7-20, año 1, vol. 1, mayo/agosto, INAH, México.

_ 2000 , "Los cantos de los linajes en el mundo colonial", discurso de ingreso a la Academia Mexicana de la Historia, en Memorias de la Academia Mexicana de la Historia, pp. 141-160, t. XLIII, México.

Ruiz Medrano, Ethelia, 2000, "Poder y justicia: Los códices jurídicos como un mecanismo de negociación indígena, 1550-1600", ponencia presentada en la reunión organizada por Conacyt para responsables de proyectos, Oaxaca, México.
Ruz, Mario Humberto, 1994, Un rostro encubierto. Los indios del Tabasco colonial, Teresa Rojas y Mario H. Ruz directores de la colección Historia de los pueblos indígenas de México, CIESAS, INI, México.

Sahlins, Marshall, 1983, "Other times, Other Customs: The Anthropology of History”, en American Anthropologist, pp. 517-547, vol. 85 , núm. 3 .

Spalding, Karen, 1974, "El indio en la colonia: investigaciones pasadas y perspectivas futuras", en De indio a campesino. Cambios en la estructura social del Perú colonial, pp. 197-249, Instituto de Estudios Peruanos, Lima, Perú. Spores, Ronald, 1973, "Research in Mexican Etnohistory", en Richard E. Greenleaf and Michael C. Meyer, Research in Mexican History. Topics, methodology, sources, and a practical guide to field research, pp. 25-48, University of Nebraska Press, Lincoln.

Terraciano, Kevin, 1998, "Crime and Culture in Colonial Mexico: The case of the Mixtec Murder Note", en Etnohistory, 45 (4), pp. 709-745.

_ 2000, "The colonial mixtec community", en Hispanic American Historical Review, pp. 1-42, 80: 1.

__, s/f, The Mixtecs of Colonial Oaxaca. Nudzahui History and Writing, libro en prensa.

Terraciano Kevin y Lisa Sousa, 1992, "The original conquest of Oaxaca: Mixtec and Nahua and History and Myth", en UCLA Historical Journal, 12, pp. 29-90.

Todorov, Tzvetan, 1988 [1981], Mikhail Bakhtin. The Dialogical Principle, University of Minnesota Press, Minneapolis.

Trigger, Bruce C., 1982, "Ethnohistory: Problems and Prospects”, en Ethnohistory, pp. 1-19, vol. 29, núm. 1.

Van Doesburg, Geert Bastiaan, 1996, "Introducción y explicación del códice Ixtlilxochitl”, en Anders Ferdinand, Luis Reyes García y Maarten Jansen, Códice Ixtlilxochitl: apuntaciones y pinturas de un historiador, Akademische Druck und Verlagsanstalt y FCE, México.

Vansina, Jan, 1962, "Ethnohistory in Africa”, en Ethnohistory, pp, 126-136, vol. 9, núm. 2.

- 1964 [1961], The Oral Tradition: A study in Historical Methodology, Aldine, Chicago.

Villoro, Luis, 1989, Sahagún and the Limits of the Discovery of the Other, 1992, Lecture Series, Working Papers, núm. 2, University of Maryland, Department of Spanish and Portuguese, College Park Maryland.

White, Hayden, 1992, The content and the Form. Narrative Discourse and Historical Representation, The Johns Hopkins University Press, Baltimore y Londres.

Wood, Stephanie, 1998, "El problema de la historicidad de los Títulos y códices del grupo Techialoyan”, en Xavier Noguez y Stephanie Wood (comps.), De tlacuilos y escribanos, El Colegio Mexiquense-El Colegio de Michoacán, México. 